\title{
Trajetórias de pesquisadores na área de Ciências Sociais e Humanas em Saúde: compartilhando memórias de projetos, encontros e metamorfoses
}

\author{
I ${ }^{1}$ Reni A. Barsaglini, ${ }^{2}$ Leny Alves B. Trad, ${ }^{3}$ Maria Helena M. Mendonça |
}

Resumo: O artigo analisa as trajetórias docentes/ pesquisadores das Ciências Sociais e Humanas em Saúde atuantes nos programas de pós-graduação em Saúde Coletiva, considerando suas formaçōes e práticas na pesquisa, ensino e extensão. Trajetórias expressam decisóes, escolhas e empenhos pessoais em projetos que interagem com outros projetos em um campo onde se negocia a realidade. Compusemos um referencial pelos conceitos de projeto, metamorfose, campo de possibilidades e mediação de Gilberto Velho e de arenas transepistêmicas de Karin Knorr-Cetina. Os dados advêm de questionário online, respondido por 59 docentes pesquisadores e 19 entrevistas (ambos semiestruturados) observando-se representaçáo regional e geracional. Analisamos os relatos pessoais em contexto articulados a acontecimentos, eventos, projetos, pessoas e instituiçóes. Os resultados trazem as inserçôes e atuaçôes: pela formação e pesquisa como pontos de partida, encontros e metamorfoses; e pelas interaçōes dentro e fora da comunidade científica pelo ensino, extensão e ativismo. As trajetórias delineiam-se por projetos pessoais e coletivos em meio às circunstâncias imediatas, mudanças geracionais e tendências de maior duraçấo, tensionando em supostas fronteiras e transcendendo dos campos disciplinares para outros setores sociais. Neste processo, enredam-se agenciamentos cotidianos, sem menosprezar heranças históricas, políticas e sociais que interseccionam os projetos na construção das trajetórias pessoais e institucionais. Palavras-chave: Saúde Coletiva; Ciências Sociais e Humanas em
Saúde; trajetórias profissionais.

\author{
${ }^{1}$ Instituto de Saúde Coletiva, \\ Universidade Federal de Mato \\ Grosso. Cuiabá-MT, Brasil \\ (barsaglinireni@gmail.com). \\ ORCID: 0000-0002-8903-2695 \\ ${ }^{2}$ Instituto de Saúde Coletiva, \\ Universidade Federal da Bahia. \\ Salvador-BA, Brasil (trad@ufba.br). \\ ORCID: 0000-0002-8762-4320 \\ ${ }^{3}$ Escola Nacional de Saúde \\ Pública, Fundação Oswaldo \\ Cruz. Rio de Janeiro-RJ, Brasil \\ (mhelenam@ensp.fiocruz.br). \\ ORCID: 0000-0002-3917-9103
}

Recebido em: 27/08/2019 Aprovado em:25/03/2020 Revisado em: 15/10/2020 


\section{Introdução}

A criação da Associação Brasileira de Saúde Coletiva (Abrasco) em $1979^{1}$ pode ser apontada como um dos marcos fundacionais no percurso de construção da área das Ciências Sociais e Humanas em Saúde (CSHS). Desde então, a área experimentou significativa expansão de seus atores, práticas e espaços de atuação, sendo notáveis os avanços alcançados em termos de sua institucionalização no campo da Saúde Coletiva. Tal configuraçáo justificou o investimento em ampla pesquisa que traçou um perfil da área, privilegiando o contexto dos programas de pós-graduação em Saúde Coletiva - PPGSC (TRAD et al., 2018). ${ }^{2}$ Inspirado por fundamentos da Teoria Ator Rede (LATOUR, 2012), o estudo procurou mapear quem são os atores (docentes e/ou pesquisadores das CSHS que atuam nos PPGSC), como atuam (práticas, relaçôes, redes sociotécnicas), o que caracteriza seus rastros (produçóes, narrativas), assim como as controvérsias suscitadas por seus movimentos e produçóes.

Neste artigo recortamos da pesquisa referida, um dos aspectos contemplados na questão relativa a "quem são os atores", que diz respeito às peculiaridades das suas trajetórias dentro do campo. Vale notar que o tema das trajetórias dos atores da área foi abordado por Ianni et al. (2014) que analisaram, especificamente, o perfil dos presidentes da Abrasco e dos coordenadores das Comissôes de Ciências Sociais no período de 1995 a 2011, alinhado com diferentes ediçóes de Congressos nacionais de CSHS. Desta feita, o interesse se dirige às trajetórias de sujeitos que integram o quadro de docentes de PPGSC, credenciados na condição de permanente ou colaborador, considerando escolhas e projetos relativos à formação ou aos elementos instituintes de suas práticas (na pesquisa, ensino ou extensão).

Para analisar tais trajetórias, recorremos especialmente, ao conceito de projeto, que se refere à conduta organizada para atingir finalidades específicas, tornandose antecipação de trajetórias, porém sem conotação linear, determinística, voluntarista, fixista e normativa, dado o caráter relacional e interacionista dos projetos individuais e coletivos (de grupos, instituições, organizaçóes), nos termos de Gilberto Velho (2003).

A trajetória élocalizada e tortuosa, permeada por irregularidades, imprevistos, (des) continuidades, merecendo atenção não só o seu sentido, ritmo, direção, mas também suas bordas e como expressáo de projetos, tentando perceber o que possibilitou uma configuração particular (VELHO, 2003). Em meio a esta heterogeneidade, projetos 
individuais e coletivos se influenciam mutuamente impelindo dinamismo por contínuas negociações e ajustes, aproximando-se da análise de carreiras (HUGHES, 2005; DE LUCA et al., 2016).

Tal plasticidade, em que projetos podem ser alterados em função da negociação ou cotejamento com outros projetos, é tratada por Velho (2003) pelo conceito de metamorfose. Ora, projetos não operam num vácuo, mas em interação com outros e em universos específicos, que podem ser, por vezes, confluentes, consensuais e colaborativos, como, também, contraditórios e conflitantes, designados em um campo de possibilidades que disponibiliza aos envolvidos, alternativas construídas no processo sócio histórico com potencial interpretativo e de ação no mundo (VELHO, 2003).

Se a trajetória reporta à metamorfose impelida pelo contato e trânsito por diferentes domínios sociais remete, também, às fronteiras. Estas, com seus limites simbólicos e físicos, demarcam diferenças, ao mesmo tempo, que precisam delas para existir (Souza, 2014), sendo terreno poroso e fluido onde se dão os encontros, contatos, afetos, trocas, trânsitos, passagens, fluxos, negociaçóes. E neste ponto, evocamos outro conceito de Velho (2001): a mediação, pois é através dela que fronteiras são inventadas, cruzadas, reiteradas, flexibilizadas. Ao transitar em diversos domínios socioculturais transita-se, também, entre diferentes estilos de vida, experiências, interesses e projetos havendo política nos encontros cotidianos com crises, alianças, rompimentos que perpassam o contínuo processo de negociação da realidade, diz o autor. A possibilidade de lidar com vários códigos e viver diferentes papéis sociais, num processo de metamorfose, dá a indivíduos específicos a condição de mediadores quando implementam de modo sistemático essas práticas (Velho, 2001).

Além disso, por tratamos de profissionais do universo da ciência, consideramos oportuno incorporar a categoria arenas transepistêmicas, de Knorr-Cetina (1996), referente aos processos de interação entre diferentes atores (agências financiadoras, administradores, indústrias, editores, diretores de instituiçôes científicas, fornecedores etc.) e argumentos (científicos ou não) no bojo da comunidade científica. Avessa à visão de fechamento da prática cientifica e de seus praticantes, esta noção mostra o imbricamento dos mundos social e científico, as relaçôes entre os cientistas e destes com o mundo exterior (KNORR-CETINA, 2005) esmaecendo suas fronteiras. Assim, o produto da ciência não resulta da ação autônoma e isolada dos cientistas ou de objetivos individuais (o próprio interesse é fruto de oportunidades e negociação), havendo relaçôes de dependência mútua em termos de recursos e suportes de 
elementos e agentes externos que dela participam, decorrendo a prática científica de construçôes contextuais, contingentes e atravessada pela estrutura de interesses envolvidos (KNORR-CETINA, 1996; 2005; 2007). Sem descurar dos circuitos macroepistêmicos, a autora considera o ambiente cultural das microinteraçôes na produção do conhecimento.

Parte-se, assim, do pressuposto de que a trajetória é a expressão retrospectiva de um percurso construído por decisóes e escolhas empreendidas por empenhos pessoais a partir de projetos (prospectivos) que interagem com outros projetos, sendo influenciados e mediados por objetividades e subjetividades que operam em um campo de possibilidades onde transita-se e negocia-se a realidade. E estes movimentos transcorrem colocando em contato pesquisadores e não pesquisadores, pessoas e instituições em diferentes espaços e respectivos elementos materiais e simbólicos sendo, então, interações que se dão em zonas fronteiriças entre mundo social e científico.

\section{Sobre a metodologia}

No fluxo da vida cotidiana a trajetória é apreensível, retrospectivamente, pelas lembranças do vivido que decorrem de interpretação em edição/filtros àquilo que nos tocou e afetou e marcou como experiência a ser narrada (LARROSA, 2015). Neste sentido, uma das vias privilegiadas neste estudo, consistiu no convite aos nossos interlocutores para vasculhar em suas memórias acontecimentos e vivências, evocáveis e localizadas num tempo, espaço e num feixe de interaçóes, significativos à conformação de seus projetos profissionais. Entende-se que aquele que lembra está sempre inserido e habitado por outros grupos de referência, por isso a memória é trabalho individual e grupal (HALBWACHS, 1990) e a tentativa de articulá-la pelo relato depende da organização, a posteriori, destes fragmentos ao longo da trajetória (VELHO, 2003).

Assim, este trabalho deriva de pesquisa mais ampla que abrangeu 68 PPGSC (triênios 2004-2006, 2007-2009, 2010-2012) e contemplou uma amostra de 176 docentes vinculados à área das CSHS, constituída com base nos seguintes critérios: atuação e inserção de liderança do pesquisador na área como, por exemplo, propor GTs, coordenar fóruns, participar de comissôes; desenvolver práticas de ensino, pesquisa e extensão associadas a área; ter formação em Ciências Sociais e Humanas 
(graduação e/ou pós-graduação); figurar no rol do corpo docente (permanente ou colaborador) de PPGSC em, pelo menos, um dos três triênios contemplados.

Dentre as fontes de coleta adotadas, duas serão privilegiadas aqui, precisamente por ter requerido dos participantes o referido exercício de memória. A primeira é um questionário on line (anônimo), enviado à totalidade da amostra de docentes/ pesquisadores das CSHS e que contou com 59 formulários respondidos. Considerouse satisfatório o perfil desta subamostra por refletir um padrão semelhante ao universo maior: concentração no Sudeste e participação expressiva do Nordeste; predomínio feminino e sujeitos da chamada geração intermediária entre mais nova e mais antiga. Este instrumento incluiu uma questão aberta com o enunciado: "descreva brevemente sua trajetória de inserção na área de Ciências Sociais e Humanas em saúde" e que exploramos no presente texto.

A segunda fonte consistiu em entrevistas realizadas via Skype com docentes/ pesquisadores pinçados do grupo maior, cuja seleção considerou o recorte geracional descrito abaixo e sua auto objetivação, seja pela inserção institucional e formação acadêmica, o que permitiu contato inter e geracional e tempo de participação no programa de pós-graduação, somado à diversificação do perfil pelo ponto de vista regional. Excluíram-se os que não atenderam aos convites, não dispunham de tempo ou consideraram já ter respondido ao questionário. Totalizamos, assim, dezenove entrevistas (em um misto do modelo semiestruturado e narrativo), configurando uma amostra que seguiu o perfil mencionado da amostra maior. Nossos interlocutores foram convidados, incialmente, a situar "seu lugar" no campo da Saúde Coletiva e, em seguida, a discorrer sobre suas experiências e impressóes sobre as práticas de pesquisa, ensino e extensão no âmbito da pós-graduação.

Para operacionalizar o recorte geracional emprestamos a taxonomia adotada por Ianni et al. (2014) para classificar as geraçóes dos atores da área segundo sua participação nos momentos de constituição, institucionalização e consolidação do campo da Saúde Coletiva e da área de CSHS. Esta tipologia orientou os três códigos da identificação dos entrevistados - GH, GI e GN - que correspondem, respectivamente, à geração de históricos, da institucionalização e da nova geração. Convém salientar o alinhamento com uma concepção que reconhece na coincidência etária como elemento apenas potencial valorizando, de fato, o "laço geracional" que se dá através do compartilhamento de experiências e, sobretudo, de eventos que irrompem sobre a continuidade histórica, marcando e transformando dada geração 
(MANNHEIM, 1982). Por certo, embora não devam ser ignoradas, as fronteiras que separam as geraçôes são borradas ou maleáveis e, como tal, sujeitas a atravessamentos e ambiguidades (BAUMAN, 2007, p. 373).

$\mathrm{Na}$ análise, levou-se em conta que aquilo que as pessoas dizem individualmente pode ser breve, mas foi pinçado de uma totalidade, de modo que é possível vislumbrar a quais acontecimentos, eventos, pessoas, instituiçóes estão articuladas o objeto em questão - a trajetória; pois, o que é transmitido ultrapassa o caráter individual e se insere nas coletividades onde a pessoa está integrada e perpassada por influências diversas que se cruzam por/nas suas açôes e de outros (QUEIROZ, 1987).

A pesquisa mais ampla de onde deriva este artigo (TRAD et al., 2018), foi aprovada pelo Comitê de Ética do Instituto de Saúde Coletiva-UFBA (Parecer $n^{\circ}$ 708.494, de 27/5/2014). Visando preservar o anonimato, adotamos os códigos QP, QP, QP e assim por diante, seguida de numeração aleatória, para dados extraídos do "Questionário Pesquisador" (Qn), e GH, GI e GN para os dados das entrevistas, conforme tipologia supracitada. Além disso, para evitar riscos de identificação dos nossos interlocutores, tendo em vista que o leitor preferencial deste artigo faz parte do mesmo universo pesquisado, nos trechos extraídos de entrevistas ou dos campos abertos dos questionários eletrônicos foram suprimidas informações relacionadas a instituiçôes, funções, nome de projetos ou outros dados desta natureza.

\section{Inserçóes pela formação aos espaços da pesquisa: pontos de partida, encontros e metamorfoses}

Elegendo a formação na graduaçáo como um ponto de partida na trajetória dos participantes, destacam-se dois perfis principais: aqueles que se graduaram em cursos da área de Ciências Sociais ou Humanas (Sociologia, Antropologia, Psicologia, História etc.) e foram atraídos pelo campo da Saúde Coletiva que são 47,5\% dos docentes; ou em cursos da área de saúde, sendo notável a referência à Medicina e, posteriormente, foram iniciados e fundamentaram sua formaçáo em CSHS na pós-graduação, seguida pela docência e pesquisa e a busca pela pós-graduação interdisciplinar que foram 44,6\%. A entrada pelas CSH parece conferir aos primeiros (destacando-se a geraçáo que desbravou o campo e aquela que despontou na fase de sua institucionalização) maior legitimidade ao pertencimento à área e, ao mesmo tempo, a percepção mais aguçada quanto à responsabilidade de reproduzir 
ou transmitir o saber específico da área seja no ensino, na pesquisa etc., sempre em movimento de mão dupla. Como referem:

Eu tô há mais de trinta anos na área da Saúde Coletiva, né. Eu fiquei X anos só na área de Sociologia na [IES pública], quando eu era professora do departamento de Ciências Sociais no Instituto de Filosofia e Ciências Sociais da [IES pública] [...] Em XX [ano], então, eu comecei a trabalhar [...] no programa que tava sendo criado do mestrado em Medicina Social [...] me pareceu algo muito avançado aí eu resolvi entrar neste programa [...] havia já uma busca de participação das Ciências Humanas nesse programa (GH1).

Iniciei em XX [ano] como cientista social no Departamento de Medicina Social da [IES privada], área de Ciências Sociais na Saúde, dando aula para alunos de graduação em medicina. A partir de XXXX e XXXX [anos] passei a ministrar disciplinas também na graduação de enfermagem e fonoaudiologia da mesma instituição de ensino (Q24).

Cientista social formada na graduação pelo IFCS, Mestrado e Doutorado em Ciências Humanas e Saúde; professora e pesquisadora da área em diferentes instituiçóes; desde o final da graduação pesquisando temas relativos à saúde e lecionando Ciências Sociais voltadas para a saúde. (Q29).

A formação de profissionais com foco na SC originou-se na pós-graduação lato sensu nos cursos de formação de especialistas em Saúde Pública ou Comunitária, que titulavam os sanitaristas, no âmbito do curso de Medicina e de relaçóes de parceria entre academia e serviços sociais e de saúde. Encontramos no caso desse estudo a metade de nossa população entre 1969 e 1979 com, pelo menos, um curso de especialização. Nesta fase, há um equilíbrio na presença de docentes oriundos da graduação em CSH, em especial da Sociologia, e da área biomédica, com destaque para Medicina.

Em sintonia com a noção de laço geracional (MANNHEIM, 1982), já referida, em diferentes relatos encontramos a alusão a alguns fatos transformadores. Particularmente entre a geração histórica encontramos reminiscências de momentos de grande ebulição, negociaçôes de projetos travados no campo da Saúde Coletiva em constituição, um tempo no qual "vivia-se o impacto da Reforma Universitária de 1968, de um lado, e, de outro, toda a crítica que se estabelece ao modelo médico hegemônico, assim como se discutiam as diferenças entre Medicina Preventiva, Medicina Social e Saúde Pública” (NUNES, 2005, p. 21).

Além dos acontecimentos marcantes, chama a atenção o destaque conferido em muitas narrativas ao contato presencial travado com lideranças históricas constitutivas do campo da Saúde Coletiva e das CSHS (os relatos estão repletos deles). Se a memória é constituída por acontecimentos, personagens e lugares, o 
contato proporciona o que Pollak (1992) chama de acontecimentos "vividos por tabela”, ou seja, vivido por personagens, grupo, coletividade à qual a pessoa se sente pertencer. São trajetórias que se tocam e se afetam, confluem ou conflitam, mas importante que promovem açôes, mobilizam e motivam os percursos. E esta convivência mostra-se estimulante e relevante apresentando caminhos trilhados e convocados a trilhar em conjunto, compondo campo de possibilidades fecundo à constituiçáo e ancoragem da trajetória dos pesquisadores nas CSHS.

[...] já no primeiro curso que eu fiz que era aplicado por Ricardo [Bruno] Gonçalves, [...] Introdução à Medicina Preventiva e eu fiquei encantado com essa coisa da reflexão teórica né, do campo, que Ricardo trazia, que juntava justamente as Ciências Sociais, Filosofia e Medicina [...] uma das figuras fundadoras do departamento foi Cecília Donnangelo [...], foi aluna do [Luis] Pereira que foi um importante sociólogo aqui da [IES pública], né. [...] Depois da Cecília, também veio a Amélia Cohn, que foi também um nome importante da consolidaçáo da área do departamento e ela, não só, foi importante na formação de geraçẫo Residentes (GI1).

[...] eu lia as pessoas da área das Ciências Sociais e Humanas em Saúde: era essa a bibliografia que eu procurava. Foi através do contato com essa bibliografia que eu busquei uma residência em Saúde Mental [cita um estado], entâo, na década de XX [...] quando eu me tornei [docente] no Instituto de Medicina Social. Poxa vida, pra mim foi uma honra, né, fazer parte de uma instituiçáo como aquela, né, como essa que eu trabalho hoje. Quer dizer, é simplesmente o Instituto de Medicina Social, simplesmente onde trabalharam X, Y, Z [cita lideranças históricas da área] (GN2).

É preciso reconhecer, também, o quanto a trajetória individual é condicionada pela estrutura acadêmico-institucional disponível, colocada como alternativa em um campo de possibilidades (VELHO, 2003), corroborando as ponderaçôes de Ortiz (2010, p. 126), quando diz que: "há momentos em que a escolha é possível, ela se faz, contudo, dentro de um quadro no qual as alternativas encontram-se objetivamente demarcadas". No caso em análise a inexistência, até recentemente, da graduação em Saúde Coletiva, fez da pós-graduação (lato ou stricto sensu) a porta de entrada para a formação em Saúde Coletiva, conduzindo, em muitos casos, à filiação às CSHS. Possibilidades engendradas nas esferas da política nacional de educação, ciência e tecnologia, seja quando criou o Sistema Nacional de Pós-Graduação no País, impulsionando a expansão de cursos de mestrado e doutorado em todas as áreas do conhecimento ou quando implantou a modalidade profissionalizante, na esteira da ampliação do stricto sensu de modo geral, com desdobramentos na área da saúde. Dentre os que se inseriram pelo mestrado e doutorado, nota-se nos relatos seguintes. 
[...] comecei a trabalhar em Saúde Coletiva a partir do mestrado [...] em Saúde Comunitária, lá nos anos de 1980 do século 20. E fui, comecei a fazer o curso e ao concluir o mestrado que ainda era assim. Meu interesse inicial tinha sido Saúde do Trabalhador porque, enfim, a gente ainda tinha muita influência marxista, né, na nossa formação (GH4).

Fiz mestrado e doutorado na, então, Medicina e Preventiva e Social da [IES pública] após vários anos de prática profissional como [cita categoria profissional] na Atençâo Básica. Meu tema de mestrado foi a medicalizaçáo social derivada das práticas de cuidado profissional, e no doutorado houve uma inserçáo em autores da epistemologia/história e sociologia da ciência. Isso levou-me, inevitavelmente, às CSHS (Q51).

No bojo do lato sensu, temos, num primeiro momento, uma profusão de cursos de Medicina Preventiva, Medicina Social e Saúde Pública, os quais figuram em várias das trajetórias descritas. Posteriormente, a criação das residências multiprofissionais, alinhadas com o projeto de reestruturação do modelo de atenção no país (pela Estratégia Saúde da Família) que rompe com a exclusividade da clientela médica, potencializa a penetração das CSHS no processo de formação. Os excertos são ilustrativos:

Fiz o curso de especialização em Saúde Pública da Ensp/Fiocruz e, em seguida, mestrado no IMS/UERJ, tendo sido convidada a participar de pesquisa sociológica na área da prevenção da Aids, sexualidade e reprodução (Q7).

Após uma formação no antigo curso de especialização em Saúde Pública, tendo concluído o curso de graduação em direito, comecei a organizar o campo de direito sanitário no Brasil, a partir de 1987 (Q35).

Ao concluir o curso médico na [IES pública], e muito estimulado por meus contatos com o IMS, fui fazer minha especialização no Programa de Residência Médica em Medicina Preventiva e Social da [IES pública] [...]. Fiquei encantado com a combinação entre uma prática aplicada de atençáo primária à saúde, de grande delicadeza e qualidade no Centro de Saúde Escola, e sua articulação com o sofisticado empreendimento conceitual que buscava articular as Ciências Humanas com as Ciências da Saúde e a prática de Saúde Coletiva. Envolvi-me, especialmente, com a reflexão histórica e a epistemologia (Q13).

Como as pessoas, os projetos têm ação e mudam ou as pessoas mudam através de seus projetos, pondera Velho (2003) através da noção de metamorfose. Ao referir-se às filiações a cursos de graduação ou de pós-graduação, encontramos referências às escolhas motivadas pelo interesse em fortalecer abordagens e práticas interdisciplinares, assim como ressignificar percursos formativos, tendo em vista a natureza e complexidade do objeto. Entram em cena o jogo de unidade e diferenciação de Velho (2005), pelo qual projetos individuais e coletivos são 
negociados e se retroalimentam naquele campo de saberes e práticas podendo reproduzi-los, posteriormente, mas não sem personalizá-los. Como referem:

Minha inserção no campo das Ciências Sociais e Humanas em Saúde surge da constatação que explicar o estado de saúde de grupos populacionais implica, necessariamente, na compreensão de que os comportamentos em relação à saúde são, ao mesmo tempo individuais e sociais [...] essas questôes me levaram, gradualmente, a substituir a abordagem obtida na graduação em Enfermagem. [...] Sem subestimar a importância desta profissão, percebi a necessidade de ampliar meus conhecimentos [...] de modo a ampliar meus conhecimentos no campo da Saúde Pública. Obtive um diploma... [informa três diplomas obtidos em outro pais]. Dada a complexidade das realidades estudadas, busquei um maior aprofundamento do conhecimento nas Ciências Sociais, incluindo os aspectos teóricos e metodológicos [...] os diferentes aspectos - material e quantitativo, qualitativo e simbólico [...] pude compreender a necessidade de complementar e enriquecer os dados antropológicos por outros olhares disciplinares, fazendo muitas vezes um caminho inverso, da Antropologia à Saúde Pública. (Q5).

Me graduei em Psicologia... em 1987 e, em seguida, fiz formação complementar em Psicanálise (dois anos) e, paralelamente, integrava um grupo de estudo voltado para psicologia social e comunitária. [...] no Programa de Doutorado em Ciências Sociais na Universidade $\mathrm{X}$ [instituição de outro país]. Dentre os objetivos deste programa, destaco particularmente dois: dispor de um marco adequado para realização e transmissão dos avanços científicos em Ciências Sociais (fundamentalmente Sociologia, Antropologia, Psicologia, Economia) e suas relaçóes com a saúde e o setor sanitário; (2) formar os/as novos/as investigadores e propor equipes de investigação para enfrentar com êxito o desafio colocado pelas Ciências Sociais contemporâneas através de suas técnicas e metodologias. (Q55).

Movendo o debate para as alusóes à pesquisa em CSHS contata-se que, se a especialização e progressiva expansão experimentada neste segmento a partir dos anos noventa constituiu um dos fatores chave para institucionalização da área na Saúde Coletiva (CANESQUI, 2007) representou, também, para muitos interlocutores, a oportunidade de inserção e/ou fixação em PPGSC.

Ao final do curso de Ciências Sociais (bacharelado) iniciei como auxiliar de pesquisa na área de violência e saúde. [...] Como iniciei na Saúde Coletiva nos fins dos anos 1980, havia grande demanda por profissionais que ensinassem métodos das Ciências Sociais. Assim, dediquei-me a aprofundar e compartilhar tais conhecimentos nos programas de pós-graduação onde atuo (Q20).

Comecei a trabalhar no Instituto de Medicina Social da [IES pública] em XX [ano] num programa [...] um projeto multicêntrico sobre gravidez na adolescência. E já em $2000 \mathrm{eu}$ comecei como [cita uma função] com uma bolsa do CNPq [...] Em XXXX [ano] eu fiz concurso e fiquei como professora adjunta de XXXX a XXXX [periodo de 6 anos], né, participando do departamento de $[\mathrm{XX}]$ que é o departamento mais vinculado às Ciências Humanas dentro do IMS (GN3). 
Minha trajetória teve início como assistente de pesquisa em projetos do Núcleo de Estudos Político-Sociais em Saúde do [departamento de IES pública]. Seguiu com um mestrado na área de concentração de Saúde e Sociedade dentro da [IES pública] e com um doutorado quatro anos após a conclusão do mestrado em Ciências Humanas/Sociologia no [IES pública]. Essas escolhas se deram em função da aquisição de referências em trabalho com metodologias qualitativas de pesquisa na interface saúde, cultura e doença (Q1).

Percebe-se, assim, que subjaz o potencial de metamorfose dos aspirantes a pesquisadores das CSHS diante da oportunidade colocada por projetos existentes e possibilidades institucionais para conciliar e forjar os seus próprios. Estes tipos de inserçôes e experiências, em muitos casos, foram decisivos/determinantes para definir temas e linhas de pesquisa na etapa inicial ou ao longo da carreira de pesquisador

Iniciei minha trajetória em 1985, desenvolvendo pesquisa sobre as relaçóes entre Direito e Medicina, em torno do surgimento dos manicômios judiciários no Brasil. Meu doutorado abordou a história da luta contra a sífilis entre nós. Atualmente venho trabalhando com temas vinculados à sexualidade e direitos sexuais (Q6).

Sou médica sanitarista e aproximei-me da área de Ciências Sociais em Saúde através da Antropologia voltada para estudos de populações indígenas e mestiças na Amazônia (Q14).

Outro aspecto especialmente remarcado nas narrativas de alguns entrevistados, diz respeito à constatação de que a valorização da área de CSHS pelas instituiçôes revela-se fundamental para viabilizar seu pleno desenvolvimento (por exemplo, pela definição de vagas para concursos ou apoio concreto aos grupos atuantes na área) o que inclui, certamente, a consolidação do ensino e da pesquisa. Com base em muitos relatos, pode-se dizer que a UERJ, mais especificamente, o programa de pósgraduação do Instituto de Medicina Social, revela-se caso exemplar nesta direção. $\mathrm{O}$ relato abaixo ilustra bem esse reconhecimento:

Eu acho que o Instituto de Medicina Social e o nosso programa de pós-graduação lá tem uma trajetória muito específica em relação à valorização do campo das Ciências Sociais. Ele é um programa historicamente em que a área de Ciências Humanas sempre foi muito importante. Entáo a gente teve uma trajetória de pesquisadores de professores importantes que passaram por lá (GN3).

Importante registrar, também, que o Plano de Reestruturação e Expansão das Universidades Federais/Reuni de 2007, foi um fato que contribuiu claramente para a ampliação e fixação de quadros de docentes e pesquisadores da área. Em muitos PPGSC, os novos concursos foram viabilizados graças à implantação do curso de Graduação em Saúde Coletiva, cuja base disciplinar, favoreceu a incorporação de 
novos docentes da área de CSHS. Neste sentido, não há dúvidas que o Reuni abriu as portas para uma transição geracional e potencializou a renovação dos quadros docentes incorporados nas décadas de 1960 e 1970. Em contrapartida, atualmente, há muito mais incerteza quanto às garantias de substituição da legião de lideranças que vem se aposentando dos programas mais consolidados da pós-graduação em Saúde Coletiva, haja vista as configuraçóes das políticas em curso na educação superior e na pesquisa.

\section{Ampliando os trânsitos e as interaçóes dentro e fora da comunidade científica: inserçóes pelo ensino, extensão e ativismo}

Sendo a prática científica ou acadêmica contextual e contingente (Knorr-Cetina, 1996), ela se define e renova em função dos múltiplos contextos, acontecimentos e interesses circundantes. Neste tópico, nos deteremos na inserção dos pesquisadores das CSHS no ensino e, principalmente, na chamada prática extensionista ou de cooperação técnica, como preferem alguns. Assim como observado nos projetos relativos à formação e à pesquisa, mantem-se nestes segmentos a recursividade entre pessoas e instituiçóes (Hughes, 2005), que dão lugar a arranjos e articulaçóes entre os projetos, viabilizando e delimitando negociações nas arenas em tela. Veremos que ganha relevo aqui, as práticas engajadas que se institucionalizam tensionando e suscitando (re)criações de fronteiras e espaços de atuação.

A "socialização" de questôes médicas, observada nos anos de 1990, pela qual temas que eram circunscritos à medicina, transcenderam seus domínios e chegaram nas agendas dos movimentos sociais, segundo Russo e Carrara (2015), como um motor desta guinada da prática de cientistas sociais em direção à esfera social e política. São contextos e situações geradores de zonas de interação entre domínios sociais heterogêneos onde há comunicação (colaborativa, conflitiva) e são propícias à negociação, sendo que o engajamento neles compóe trajetórias relativizando a autonomia e isolamento dos pesquisadores nas suas alternativas de atuaçáo, como contam nossos interlocutores:

[...] toda a minha militância a partir da formatura se associou ao Movimento Sindical. Antes eu não tinha essa atuaçáo no Movimento Sindical, mas eu formei em 86 em 87 a gente teve a primeira Conferência Nacional de Saúde do Trabalhador que foi anterior a 88 aí [...] 86, 87... Mas ali a gente decidiu, uma parte de nós, migrar para a área de Saúde do Trabalhador. Então, ali eu comecei a atuar junto ao Movimento Sindical. E cada vez mais forte essa atuação e, até 90, passei ser assessora sindical (GN4). 


\begin{abstract}
Na graduação em [cita o curso] participei do movimento Pró-saúde Mental em [cidade] e estagiei em um hospital-dia, momento no qual o processo de Reforma Psiquiátrica local estava fervilhando. Logo em seguida fui residente em Saúde Mental em um hospital psiquiátrico no [cidade], atuando principalmente no [cita nome do serviço específico] - serviço de atenção diária em muito inspirado no trabalho da psiquiatra alagoana Nise da Silveira. Finalmente trabalhando alguns anos como psicólogo em um Centro de atenção psicossocial da Rede de atenção em saúde mental [estado]. Essa experiência profissional suscitou em mim o interesse pela investigação científica de alguns problemas (Q18).
\end{abstract}

Aqui as motivações políticas e institucionais confluem com as projeções de institucionalização das CSH nos cursos da saúde, constituindo possibilidades para inserção do profissional com tal perfil, como temos pistas pelos relatos em que o ensino é citado em primeiro plano na sua trajetória.

Estágios curriculares em Nutrição em Saúde Pública, pesquisas e orientaçôes na área de saúde indígena, estudos sobre avaliação de serviços de saúde indígena (Q2).

Trabalho na graduação e pós-graduação com educação, comunicação e saúde. Trabalho interprofissional na integralidade do cuidado, formação docente e de profissionais de saúde (Q9).

Nota-se, ainda, que projetos políticos de porte nacional atuaram como indutores ${ }^{3}$ da ampliação dos campos e das ferramentas de práticas em CSHS, no âmbito grupal e individual. Soma-se a isto o processo de especializaçáo de políticas e programas de saúde, os quais passam a focalizar segmentos sociais específicos (mulher, família, indígena etc.) e contemplam linhas próprias de financiamento de pesquisa pelo Ministério da Saúde, notadamente nas décadas de 2000, 2010 (LANGDON, 2014). Foram se ampliando, portanto, os espaços de interaçōes que comportam, tanto dimensôes científicas quanto políticas onde transitam cientistas, não cientistas e leigos e projetos são negociados - o que é próprio das arenas transepistêmicas tratadas por Knorr-Cetina (1996).

No relato seguinte, de uma pesquisadora da primeira geração, é notável a força política e a trama de projetos institucionalizados que se materializam nas organizaçôes e ganham vida pelas açôes pessoais, integrando e marcando sua trajetória. Uma prática conciliadora (cara) entre academia e serviços sociais e de saúde em que vemos confluência ao recente artigo póstumo sobre liderança histórica na área em tela (Silveira et al. 2018), mostrando a fluidez da sua trajetória com açôes articuladas de ensino, pesquisa e política na Saúde Coletiva matizada 
pela militância. Este trânsito intenso bem que faz da pessoa um mediador, como veremos mais adiante. Para o momento, segue o excerto:

De XX a XX [periodo de 06 anos] coordenei o Projeto de Integração Docente Assistencial da [IES privada] na Zona Norte do Município de [XX]. Nesse mesmo período fui docente na Residência Médica de Medicina Social da [IES], posteriormente, da Residência Multiprofissional em Medicina Social (médicos, enfermeiros e assistentes sociais) e docente dos Cursos de Especialização em Saúde pública que o Departamento realizou em convênio com as Secretarias Municipal e Estadual de XX para seus funcionários. [...] A partir de 2000 passei a ministrar disciplinas e orientar pós-graduandos do Mestrado Profissional [...]. De XX a XX [periodo de 02 anos] coordenei um mestrado do Pró-Ensino [...] Participei como representante da Faculdade dos Polos de Educação em Saúde da Família, Polo de Educação Permanente e Coordenação de Integração Ensino Serviços junto à Secretaria de Estado da Saúde de [estado]. E implantei o Pró-Saúde e Pet-Saúde no Curso de medicina (Q24).

Vale notar que a prática extensionista expressa fortemente o trânsito de docentes/ pesquisadores das CSHS no terreno da Política, Planejamento e Gestão (PPG). Conforme assinalam Russo e Carrara (2015), historicamente na pós-graduação em Saúde Coletiva, a área de PPG constituía uma espécie de "área mãe" de onde a Epidemiologia e as Ciências Sociais (mais acadêmicas) iriam se desgarrar, ${ }^{4}$ sendo que a primeira se dará internamente ao campo da Saúde Coletiva, enquanto a segunda transcenderá as duas fronteiras. Será na década de 2000 que as CSHS encontram oportunidades para se inserirem mais visível e concretamente nos serviços de saúde, inclusive por acumularem/guardarem em suas trajetórias experiências em projetos de integração ensino-pesquisa-serviço, que estão na origem mesma da área e que evolui de uma concepçáo de treinamento em serviço para formação profissional de trabalhadores em saúde.

Tais diferenciações mostram a pluralidade de matrizes de práticas e significados nas metamorfoses experimentadas na trajetória da área que amplificam, por seu turno, as possibilidades de inserção e atuação em CSHS e nos demais componentes da SC. Esses movimentos políticos de autonomização das áreas embutem especializaçôes e reafirmaçoóes disciplinares, mas não abandonam de vez a identificação com valores basilares constitutivos da Saúde Coletiva, como refletiu Velho (2003) sobre unidade e fragmentação.

Há uma miríade de acontecimentos que suscitaram dos pesquisadores da área, análises mais politizadas aliando uma posição de revelação e de denúncia a uma outra, de engajamento e ação diante das complexas realidades de saúde e 
doença (NUNES, 2014). De fato, sobressai nas práticas de caráter extensionista descritas nas trajetórias, açôes coletivas ou colaborativas conformadas pela via do engajamento político. Práticas animadas por um senso crítico, ético e de (co) responsabilização social, referidas, por vezes, sob a rubrica de militância, ativismo, implicação dos pesquisadores das CSHS. Podem ser designadas como formas de intervenção cidadã que mobilizam a ciência e que reafirmam o caráter público dos problemas sociais (NUNES, 2005).

Quando projetos individuais se veem atrelados aos interesses comunitários, entra em cena o papel de mediador do profissional das $\mathrm{CSH}$, como aquele que irá transitar entre categorias e níveis sociais distintos (VELHO, 2001). É neste lugar de mediação que se inscreve a atividade ou função de "representação", ou seja, em que fala/atua em nome de um grupo ou coletivo de forma legítima dada às filiaçóes possíveis por eleiçáo ou indicação entre pares (como inserçáo na Abrasco e suas comissóes, agências financiadoras, por exemplo), a qual aparece diluída nos relatos. Posto que envolve o trânsito por diferentes grupos, experiências, domínios sociais, instâncias políticas colaborativas, conflitivas, propositivas e deliberativas, nos parece claro que se configura como mediação, conforme a noção de Velho (2001). São experiências que se destacam com fontes privilegiadas de reflexóes e aprendizagem. Além disso, nos faz pensar sobre o que "representa ou implica a representação"? Aqui, antinomias podem se manifestar e a habilidade de mediador é exercida neste espaço transepistêmico, diria Knorr-Cetina (1996). Para além de uma dimensão individual e de ambiçóes pessoais - ainda que este prisma possa, também, estar presente - e, por vezes, contribua para (con)fundir projetos individuais e coletivos, espera-se que o compromisso com estes últimos prevaleça.

Se o trabalho de mediaçáo transcorre entre relaçóes sociais horizontais e verticais (entre pares ou não, pessoas, grupos, instâncias e instituiçôes) nas fronteiras, implica a negociação entre diferentes interesses e códigos, daí seu componente políticoinstitucional porque mobiliza poder e para além das motivaçôes, exclusivamente individuais. Neste sentido, ao se referir aos políticos profissionais com a reflexão de que "[eles] são políticos porque são mediadores e são mediadores porque são políticos" (VELHO, 2001, p. 26), pode-se dizer que os profissionais investidos em representação e liderança são mediadores: com legitimidade conferida operam em arenas e suas fronteiras tensionando e mobilizando-as, seja para demarcação, (re) afirmação, conservação ou transformaçôes coletivas. 
Um dos desafios ou limitadores da adesão às práticas de extensão ou cooperação técnica por parte de docentes da pós-graduação, em qualquer área, diz respeito à sua baixa valorização no sistema de avaliação da produção vigente no Brasil nos últimos anos. Dado que pode explicar, por exemplo, o sub registro deste tipo de atividade no currículo Lattes dos docentes, mesmo entre aqueles que dedicam grande parte de seu tempo e energia à projetos e ações desta natureza. Pode-se dizer que esta é uma das consequências do modelo produtivista de avaliação da pós-graduação (CAMARGO JR, 2013) e que, conforme pudemos observar, influenciam as escolhas e prioridades dos pesquisadores das CSHS, implicando em maior focalização na pesquisa e produção bibliográfica.

Por outro lado evidenciamos, também, sinais vigorosos de reaçâo da área à tendência acima referida, assim como aos riscos de certa despolitização da área. Destacamos, particularmente, um indicador associado aos seus congressos, referente ao mote do tema dos três últimos que estimula a reflexividade do campo e reitera sua filiação ao diálogo interdisciplinar e o compromisso com uma agenda política e socialmente engajada: "Circulação e diálogo entre saberes e práticas no campo da Saúde Coletiva"/2013, "Pensamento crítico, emancipação e alteridade: agir em saúde na (a)diversidade"/2016; "Igualdade nas diferenças: enfrentamentos na construção compartilhada do bem viver e o SUS”/2019. Sobretudo neste último, realizado em uma conjuntura nacional marcada por retrocessos, truculências, comprometimentos de conquistas de projetos coletivos de direitos sociais, tal como simbolizado pelo SUS, que reforçou a defesa de uma atuação implicada e propositiva na construção de lutas e resistências conjuntas. Amplia-se então a representação ao acolher e trazer para dentro do evento personagens que sofrem as políticas e as práticas sociais de saúde ou movimentos que buscam transformá-las no sentido da cidadania.

\section{Considerações finais}

As trajetórias dos pesquisadores são tecidas e retecidas, ao mesmo tempo em que dão sustentação aos projetos individuais e institucionais, em meio às circunstâncias imediatas, mudanças geracionais e tendências de maior duração. Se muitas coisas podem e desejam ser feitas, elas contam com o que o momento e o contexto incitam, viabilizam, oportunizam o que implica em jogos interativos em que interesses e recursos de domínios diversos estão em cena podendo ser mais ou menos motivadores às escolhas no percurso. 
A trajetória rememorada de pesquisadores mostra pontos em relevo da construção da prática cientifica a qual não é encapsulada, mas aberta e permeável ao mundo social não científico, como bem aponta a Sociologia da Ciência da qual nos aproximamos. Neste sentido vislumbramos particularidades de projetos individuais mediadores e mediados por elementos/projetos coletivos que transcendem a Saúde Coletiva, as CSHS, as CS para outros setores sociais mais amplamente (contexto político, econômico, educacional etc.). Desta forma, acreditamos que tais escolhas permitiram abordar as trajetórias em seu movimento, como processo aberto, em fluxo, buscando pontuar os tracejos e contornos marcantes, sobrepostos, justapostos, desviantes, deslocados, hesitantes, confluentes ao longo da inserção e atuações na área dando-se existências reciprocas (pesquisadores e área e para além dela). A metamorfose do ponto de vista individual e coletivo no caso estudado avançou para além da formação na área e incorporou a pesquisa neste processo formativo que deu suporte à sua reprodução em programas de pós-graduação interdisciplinares na área da Saúde e, por fim, à emergência da graduação multidisciplinar em Saúde Coletiva.

Aos eventos apontados pelos relatos, distribuídos/dispersos nos espaços e tempos nas biografias heterogêneas buscamos rastrear as recursividades e tornar visível o social em ação na formação de grupos (de pesquisadores da área de CSHS) que deixam seus rastros na construção do coletivo impresso nas trajetórias pessoais e institucionais. Para tanto, enredamos uma série de agenciamentos e relaçôes objetivas e subjetivas construídas cotidianamente, sem menosprezar as heranças históricas, políticas e sociais que interseccionam os projetos em curso e produzem açôes. Aí, projetos nacionais de saúde, educação, ciência e tecnologia abarcam a abordagem social da questão da saúde e exercem a mediação entre as diferentes esferas de ação que vão nortear intervençóes públicas em educação e nas práticas sociais dos serviços sociais e de saúde, incluindo a política e a gestão das mesmas. ${ }^{5}$

\section{Referências}

BAUMAN, Z. Between us, the generations. In: LARROSA, J. (Org.). On generations. On coexistence between generations, Barcelona: Fundació Viure i Conviure, 2007, p. 365-376.

CAMARGO JR, K. R. Produção científica: avaliação da qualidade ou ficção contábil? Cad Saúde Pública, v. 29, p. 1707-1711, 2013.

CANESQUI, A. M. Ciências Sociais e Saúde no Brasil. Rio de Janeiro: Ed. Hucitec, 2007. 
DE LUCA, G.; ROCHA-DE-OLIVEIRA, S.; CHIESA, C. D. Projeto e metamorfose: contribuiçóes de Gilberto Velho para os estudos sobre carreiras. Rev. Adm. Contemp., v. 20, n. 4, p. 458-476, 2016.

HALBWACHS, M. A memória coletiva. Trad. de Laurent Léon Schaffter. São Paulo: Vértice/ Revista dos Tribunais, 1990.

HUGHES, E. C. Ciclos, pontos de inflexão e carreiras. Teoria e Pesquisa, v. 46, p. 163-73, 2005.

IANNI, A. et al. Trajetórias profissionais na constituição das Ciências Socais e Humanas em Saúde na Abrasco. Physis: Revista de Saúde Coletiva. Rio de Janeiro, v 4, p. 1315-1335, 2014.

KNORR-CETINA, K. Culture in global knowledge cultures and epistemic cultures. Interdisciplinary science reviews, v. 32, n. 4, p. 361-375, 2007.

- ¿Comunidades científicas o arenas transepistémicas de investigación? Una crítica de los modelos cuasi-económicos de la ciência. REDES, v. III, n. 7, p. 129-160, 1996.

. La fabricacíón del conocimiento. Un ensayo sobre el carácter constructívista y contextual de la ciência. Bernal: Universidad Nacional de Quilmes, 2005, 368p.

LANGDON, E. J. Os diálogos da antropologia com a saúde: contribuiçôes para as políticas públicas. Ciênc. saúde coletiva, Rio de Janeiro, v. 19, n. 4, p. 1019-1029, 2014.

LARROSA, J. B. Tremores: escritos sobre experiência. Belo Horizonte: Autêntica, 2005.

LATOUR, B. Reagregando o social: uma introdução à teoria do ator-rede. Trad. Gilson César Cardoso de Sousa. Salvador/Bauru: Edufba/Edusc, 2012.

MANNHEIM, K. A questão das gerações. In: FORACCHI, M. M. (Org.). Sociologia, São Paulo: Ática, 1982, p. 67-95.

NUNES, J. A. A pesquisa em saúde nas ciências sociais e humanas: tendências contemporâneas. 2005, Disponível em: <www.ces.uc.pt/publicacoes/oficina/ ficheiros/253.pdf> Acesso em: 30 ago. 2017.

NUNES, M. O. Da aplicação à implicação na antropologia médica: leituras políticas, históricas e narrativas do mundo do adoecimento e da saúde. História, Ciências, Saúde-Manguinhos, v. 21, n. 2, p. 403-420, 2014.

ORTIZ, R. Trajetos e memórias. São Paulo: Brasiliense, 2010.

POLLAK, M. Memória e identidade social. Estudos Históricos, v. 5, n. 10, p. 200-212, 1992.

QUEIROZ, M. I. P. Relatos orais: do "indizível” ao "dizível”. Ciência e cultura, v. 39, n. 3, p. 272-286, 1987.

RUSSO, J. A.; CARRARA, S. L. Sobre as ciências sociais na Saúde Coletiva: com especial referência à Antropologia. Physis: Revista de Saúde Coletiva. Rio de Janeiro, v. 25, n. 2, p. 467$484,2015$. 
SILVEIRA, C. et al. (Inter)Conectando o mundo acadêmico e o mundo das práticas de saúde: a trajetória de Regina Marsiglia (1943-2017). Interface. v. 22, n. 66, p. 971-974, 2018.

SOUZA, M. J. Fronteiras simbólicas - espaço de hibridismo cultural, uma leitura de Dois irmãos, de Milton Hatoum. Letrônica, Porto Alegre, v. 7, n. 1, p. 475-489, 2014.

TRAD, L. A. B. et al. Perfil e contribuiçôes das Ciências Humanas e Sociais no Campo da Saúde Coletiva: Pesquisa, Ensino e Extensão - foco nos Programas de Pós-Graduação (Capes). Relatório de pesquisa. Salvador, 2018. Mimeo.

VELHO, G. Biografia, trajetória e mediação. In: VELHO, G.; KUSCHNIR, K. (Orgs.). Mediação, cultura e política. Rio de Janeiro: Ed. Aeroplano, 2001, p. 13-28.

. Projeto e metamorfose: antropologia das sociedades complexas. $3^{\mathrm{a}} \mathrm{ed}$. Rio de Janeiro: Jorge Zahar Ed. 2003.

. Unidade e fragmentação em sociedade complexas. In: SOUZA, J. Berthold, Ö. (Orgs.). Simmel e a modernidade. Brasília: Editora UnB, 2005, p. 250-67.

\section{Notas}

${ }^{1}$ Fundada como Associação Brasileira de Pós-Graduação em Saúde Coletiva, teve seu nome alterado em 2011 como reflexo de um movimento de valorização dos múltiplos atores do campo da Saúde Coletiva, principalmente pela incorporação da graduação.

${ }^{2}$ Pesquisa "Perfil e contribuições das Ciências Humanas e Sociais no Campo da Saúde Coletiva: Pesquisa, Ensino e Extensão - foco nos Programas de Pós-Graduaçấo (Capes)" (TRAD et al., 2018), financiada pelo Conselho Nacional de Desenvolvimento Científico e Tecnológico - CNPq, Edital Universal 14/2013, processo no 485728/2013-3.

${ }^{3}$ Com destaque para as finalidades e/ou áreas: integração universidade, serviços e comunidade (PRO e PET-saúde); reestruturação da Atenção Primária de Saúde (PSF, PACS); Reforma Psiquiátrica; Saúde e Ambiente; Saúde do Trabalhador.

${ }^{4}$ Russo e Carrara (2015) apontam os congressos como um dos elementos que representam tal autonomizaçâo das áreas, citando o 1º de Epidemiologia em 1990, o de Ciências Sociais em 1995 e o de PP\&G em 2010.

${ }^{5}$ R.A. Barsaglini participou da equipe de pesquisa e concepção do artigo, realizou a análise e interpretação dos dados e redação do texto; L.A.B. Trad participou na coordenação da pesquisa, na concepção e redação do texto, realizou a análise, a interpretação dos dados e a revisão final; M.H.M. Mendonça participou da equipe de pesquisa, realizou a análise, interpretação dos dados e redação do texto. 


\section{Abstract}

\section{Researchers' trajectories in Social and Human Health Sciences: sharing memories of projects, meetings and metamorphoses}

The article analyzes the teaching and research

trajectories of the Social and Human Sciences in Health acting in the Public Health postgraduate programs, considering their training and practices in research, teaching and extension. Trajectories express decisions, choices, and personal commitments on projects that interact with other projects in a field where reality is negotiated. We composed a framework for the concepts of design, metamorphosis, field of possibilities and mediation by Gilberto Velho and Karin Knorr-Cetina's transepistemic arenas. The data come from an online questionnaire, answered by 59 research teachers and 19 interviews (both semi-structured) observing regional and generational representation. We analyze personal accounts in context articulated to events, events, projects, people and institutions. The results bring the insertions and performances: by training and research as starting points, encounters and metamorphoses; and by interactions within and outside the scientific community through teaching, extension and activism. Trajectories are shaped by personal and collective projects in the midst of immediate circumstances, generational changes and longer-term trends, tensing at supposed boundaries and transcending disciplinary fields to other social sectors. In this process, daily agencies are entangled, without neglecting historical, political and social inheritances that intersect projects in the construction of personal and institutional trajectories.

> Keywords: public health; social and human sciences in health; professional trajectory. 